\title{
Implementation of Information Technology in Snakebite Management: A Case Study of Rural Maharashtra (India)
}

\author{
Abhijit A. Patil \\ Asst. Professor \\ Bharati Vidyapeeth University, \\ Y.M.Inst. Of Management, \\ Karad
}

\author{
P.P.Patil \\ Asso. Professor \\ Bharati Vidyapeeth University, \\ Y.M.Inst. Of Management, \\ Karad
}

\author{
Ajit A.Patil \\ Asst.Manager, \\ RELIANCE Energy Ltd. \\ Mumbai
}

\begin{abstract}
Information Technology plays a vital role in the snakebite management. The IT enabled GPS systems helps to the society in emergency of snakebite by transferring data. The paper focus on the present situation of Snake bites patient's status in the selected sensitive area in the rural Maharashtra. Study shows that, the worst picture of lack of communication system for assistance to the affected patients and their further treatment by the hospitals. The article suggests the Global Positioning System (GPS) Enabled computing model and the usage of Wireless Technology. The literature study shows that, such model may be the useful in snake bite affected areas. Implementation of IT in snakebite management based on the wireless technology is the need for making awareness by sharing the information about the prevention of snake bites and the treatments as first Aid to the community and the data about the victim can be made available and communicated to the further centers such as hospitals. This is an attempt to get faster and accurate information \& treatment to the snakebite victim.
\end{abstract}

\section{Keywords}

IT Implementation, Global Positioning System (GPS), Information System, Wireless Communication, Computing Model, Prevention of Snakebite, Society.

\section{INTRODUCTION}

Snakebite is aLife threatening and serious problem in rural Maharashtra [1]. There is no proper reporting system due to improper use of information and communication facility to report about the snakebite victim for in time treatment. It has been observed that the deaths due to snake bite are occurred even in the presence of advanced communication technology. It is due to lack of in time treatment of the patients. Whenever any patient is bitten by the animal like snake in the rural area, it is seen that most of the cases are dead due to lack of communication between patient and treatment system i.e. hospitals. This paper focus on the use of ICT in snakebite cases in rural Maharashtra. We evaluate that the snakebite cases admitted and referred for higher hospitals due to the unavailability of anti snake venom (ASV) [3] that would increase the chances of uncertainty. The paper suggests a proposed computing model to help and report the location and the timely availability of the anti snake venom.

\section{Present Study of Snake Bite}

India having 216 species of snakes out of that only 52 species [5] of snakes is poisonous. The time interval between snakebite and initiation of treatment is more than $6 \mathrm{hrs}$. Public Health Care centers having inadequate communication and information tools of IT Infrastructure. Our research target is to provide the snakebite information to the Hospital \& avail services to the victims \& villagers directly through mobile communication system.

Following snakebite sample cases were collected and studied from the Department of the Dr Shankarrao Chavan Government Medical College and Hospital, Vazirabad, Nanded District, Maharashtra State, India

Table 1: Snake bites cases per year from 2000-2010.

\begin{tabular}{|c|c|c|c|}
\hline Year & $\begin{array}{c}\text { Snake bite } \\
\text { cases }\end{array}$ & $\begin{array}{c}\text { Death from } \\
\text { snake bite }\end{array}$ & $\begin{array}{c}\text { Percentag } \\
\text { e (\%) }\end{array}$ \\
\hline 2000 & 460 & 29 & 6.30 \\
\hline 2001 & 570 & 34 & 5.96 \\
\hline 2002 & 540 & 33 & 6.11 \\
\hline 2003 & 609 & 27 & 4.43 \\
\hline 2004 & 645 & 34 & 5.27 \\
\hline 2005 & 545 & 25 & 4.59 \\
\hline 2006 & 625 & 23 & 3.68 \\
\hline 2007 & 603 & 29 & 4.81 \\
\hline 2008 & 438 & 14 & 3.20 \\
\hline 2009 & 450 & 22 & 4.89 \\
\hline 2010 & 427 & 20 & 4.68 \\
\hline Total & $\mathbf{5 9 9 7}$ & $\mathbf{2 9 0}$ & $\mathbf{5 3 . 9 2}$ \\
\hline
\end{tabular}

Above Table shows the average death of snakebite patients is $4.90 \%$ of total snakebite cases admitted [2].

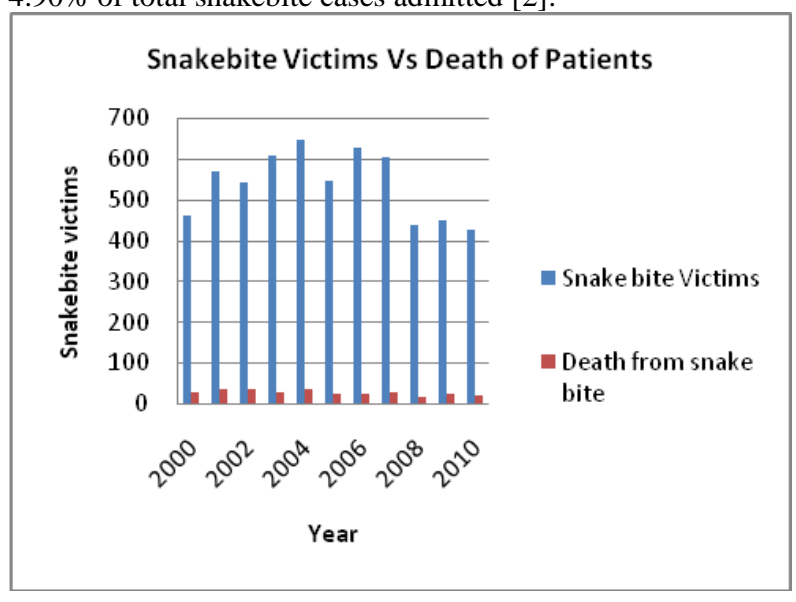

Graph 1: Snakebite Victim Vs Death of Patients 
Table 2: Snake bite Incidence quarterly in 2000-2010 yrs.

\begin{tabular}{|c|l|c|c|}
\hline $\begin{array}{c}\text { Sr. } \\
\text { No. }\end{array}$ & $\begin{array}{l}\text { Month (2000- } \\
\text { 2010) }\end{array}$ & $\begin{array}{c}\text { Total } \\
\text { Cases }\end{array}$ & Percentage (\%) \\
\hline 1 & Jan-March & 450 & 7.50 \\
\hline 2 & April-June & 870 & 14.51 \\
\hline 3 & July-Sept. & 3372 & 56.23 \\
\hline 4 & Oct-Dec. & 1305 & 21.76 \\
\hline \multicolumn{2}{r|}{ Total } & $\mathbf{5 9 9 7}$ & $\mathbf{1 0 0}$ \\
\hline
\end{tabular}

Table shows the quarterly snakebite incidence occurred in rural area of Nanded District in Maharashtra, India.

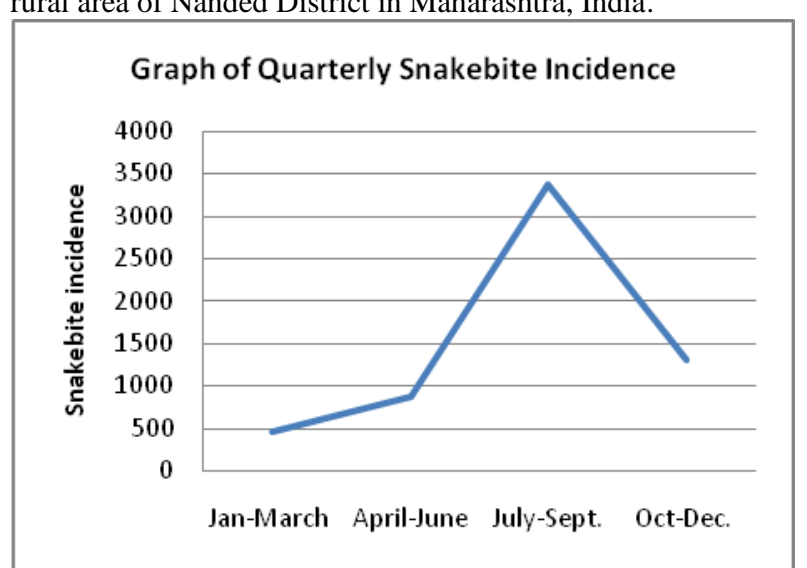

\section{IT Enabled Computing Model for the Treatment of Snake Bites}

\subsection{Internal Mechanism of RAC (Rural Assistance Center) Computing System:}

Toll free call number is assigned to RAC Cell by Telecommunication Exchange. When Incoming call (toll free call) coming from GPS [6] enabled handset to RAC computing system, it is handled by GPS Tracking [7] system to track the location [8] otherwise handled by auto response machine to capture the name ,address, query information of caller and store into the database. A software based on the knowledge management accept the general description of snakebite to find out the type of snakebite and after the further process it display the data about the antisnake venom and nearest location of the hospital to get the earliest treatment.

This data will forwarded to the caller, District Health Office (DHO) and Tahsil Health Office (THO) for further processing to get quick treatment to save the life of snakebite victim.

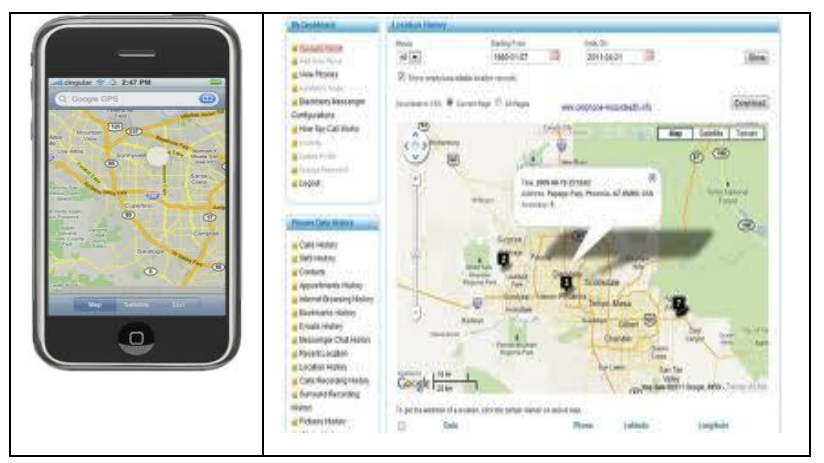

Fig.1 GPS Location Tracking System

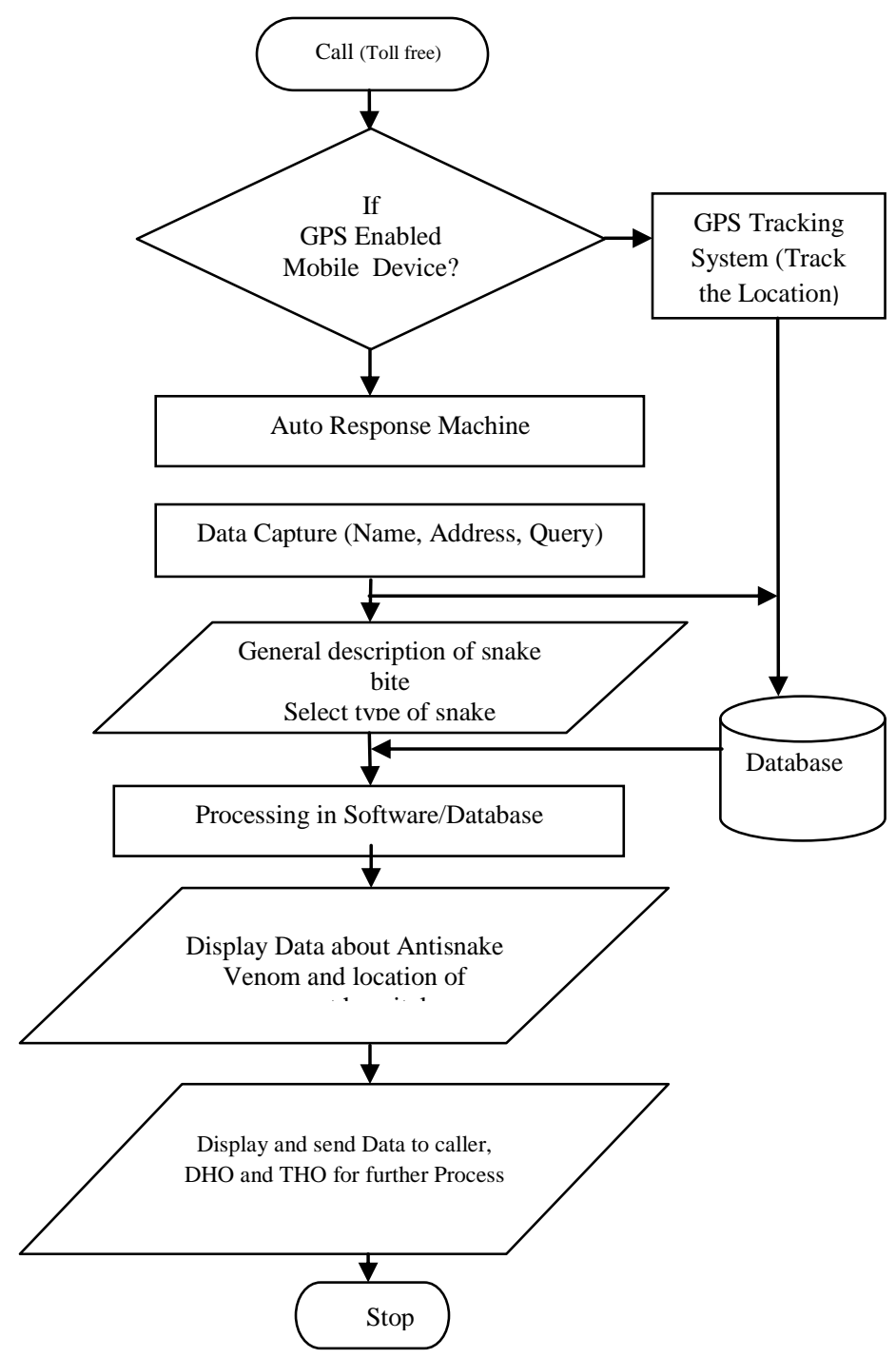

Fig 2: Flow Diagram: RAC Computing System

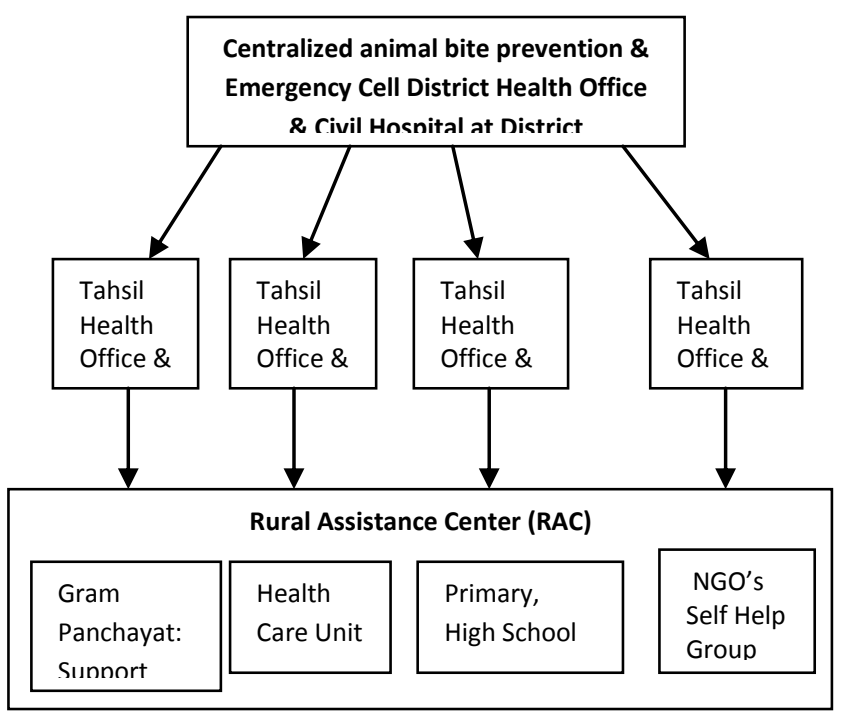

Fig 3: Snakebite awareness model 


\subsection{Working}

Rural Assistance Center (RAC) is one of the GPS [9] and Web based information cell which shares the information about snakebite prevention programmes and awareness amongst the local users about snakebites and its adverse impact communicated through using ICT based Wireless Computing Model.

\section{RAC interact with the following Units:}

i) Local Self Help Group

ii) Farmers

iii) GramPanchayat

iv) Emergency Services and Ambulance

v) Victims: Affected Users

vi) Local Teachers and Volunteers

vii) District \& Tahsil Administration

viii) Research Institutions

GPS Enabled RAC comprises a web based Computing Information Systems which is a combination of two heterogeneous technologies viz. Information Communication Technology (ICT) and Medical Technology (MT). RAC must work under the control of Regional Healthcare Center in association with the above mentioned components.

\section{Roles and Responsibilities of RAC Units}

\section{i) Local Self Help Group}

The Local self help group must be trained with the primary treatment (First Aid) given after the snakebite immediately. The Local self help group should contain two senior women members, two farmers and a snake friend as a young farmer. The Regional Health Center in association with research institution and district and Tahsil administration should provide the training of this computing system and give the updated information to the local self help group through RAC. When any snakebite incident happens then a member of Local Self Help Group should be use this system and informed so that in emergency

\section{ii) Farmers}

The farmers should be aware by the RAC with the help of Gramapanchyat Authority and Trained Teacher through Awareness Programme about Prevention of Snake bite and First Aid Treatment through Web application of RAC. These trained farmers should convey and share these information and precautions amongst the community. The RAC should display the important and Emergency mobile numbers of close by and local hospitals which provide treatment of Snake bite affected patients. In emergency the farmer should contact the above said emergency numbers and follow their instructions.

\section{iii) Grampanchyat}

The Grampanchyat authority (GRamsevek - Govt. Officio) should display the pictorial information prevention and types of snakes and basic First Aid Treatments through posters. Conduct awareness Programmes with the help of School and High Trained Teachers to the students as well as farmers in the village through interacting with the RAC system

\section{(iv)Emergency Services and Ambulance (ESA)}

Emergency Services (ESA) should be made available by Civil Surgeon through Medical Officer at closet Primary Health
Center. They should display about various types of Snakes and their Symptoms. They should have $24 \times 7 \times 366$ emergency ambulance service which will work with RAC computing system through Wireless Technology. The Ambulance should be well equipped with few support of Antisnake venom. When the Emergency cell receives any phone call or instruction from RAC computing system about snakebite patient then it is their responsibility to follow the case and support to the victim so as to save the life.

\section{v) Victims: Affected Person}

Victims or Relatives should just dial the toll free number of RAC Computing system and follow the instruction and use the data and information given by the RAC Computing System.

\section{vi) District \& Tahsil Health Administration}

District Health Administration has to establish the Emergency Cell regarding the Snake bite treatments through Tahsils in association with the Medical Research Institutions and Private Hospitals. It is now the Tahsil Health Administration who should also plan and execute the instructions received from the District for the prevention and treatment of snakebite patients in the villages. RAC computing system should be controlled by the Regional Health and District Health Administration by providing the updating medical information related to antisnake venom.

\section{vii) Research Institutions}

The Research institutions has to share the Innovative information about prevention and First aid treatments, post medical treatments by making the use of locally available resources and advanced technology. Research Institutions must provide the information about advanced medicines [4] (Anti snake venom) to the RAC and update it regularly.

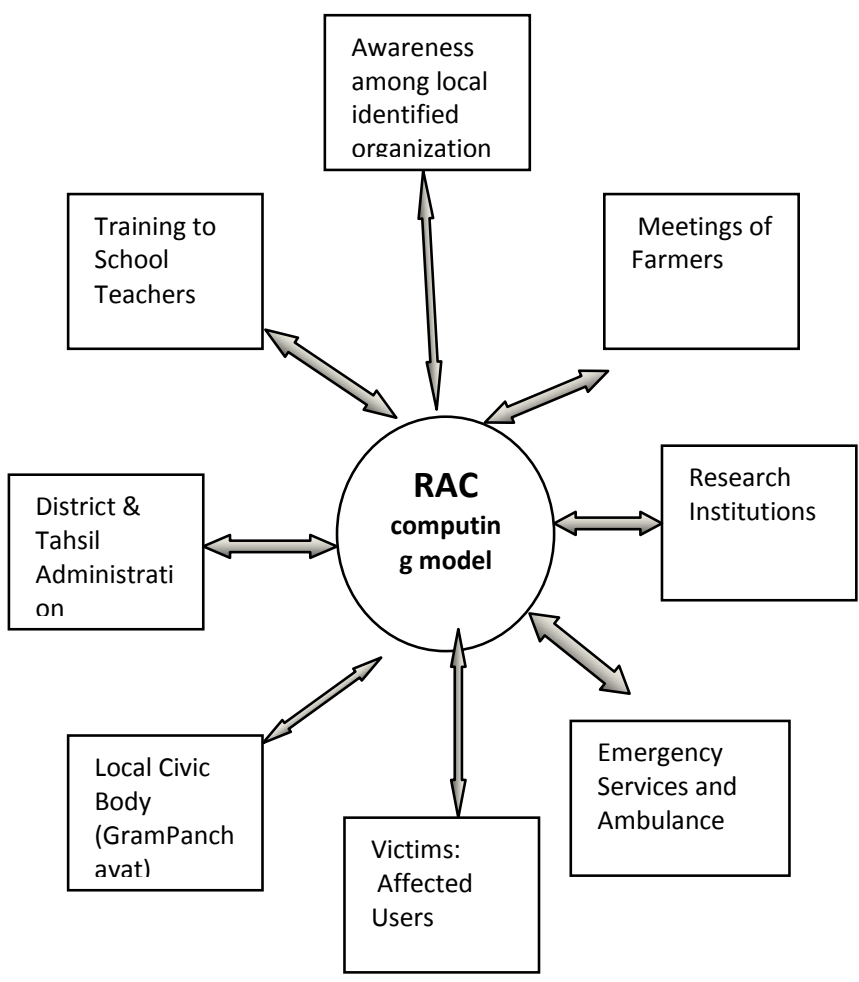

Fig 4: Interaction between RAC Units 


\section{ADVANTAGES}

- In time reporting of snakebite victim

- Quick \& accurate information available about antisnake venom stock and the location of nearest hospital for treatment

- report generated and Easy to use

- Helps to aware about prevention of snakebite $\&$ its treatment

- Highly useful to the rural community

- Emergency ambulance and services are available through this system

\section{LIMITATIONS}

- Regular data updating is required

- High bandwidth will gives better \& faster results

\section{CONCLUSION \& FUTURE STUDY}

It has been concluded that the GPS enabled [10] computing model based on wireless technology will be useful to the snakebite victims and society to save the life by providing the accurate and faster information of antisnake venom and nearest location of the hospital. High bandwidth Communication [11] system throughout the world makes it possible to implement this computing system model nationwide and worldwide in the service of society

\section{ACKNOWLEDGMENTS}

Our thanks to the District Head office, Tahsil Head Office and Dr.Shankarrao Chavan Government Medical College and Hospital Vazirabad, District Nanded, Maharashtra State, India who have contributed towards development of this research paper

\section{REFERENCES}

[1] D. P. Punde 2005: "Management of snake bite in Rural Maharashtra“, National Medical Journal of India, Vol.18 No 2

[2] I. F. Inamdar, N. R. Aswar, M. Ubaidula, S. D. Dalvi 2010: "Snake bite : Admissions at a Teritary healthcare center in Maharrashtra, India”, SAMJ, Vol. 100 No. 7
[3] Bawaskar H S, Bawaskar P H. 2002" Profile of snakebite envenoming in western Maharashtra, India". Trans R Soc Trop Med Hyg; 96: 79-84.

[4] David A Warrell, 1999 "Guidelines for the Clinical Management of Snake Bite in the South-East Asia Region" SEAMEOTROPMED, WHO, Southeast Asian Journal of Tropical Medicine \& Public Health, Vol 30, Supplement 1

[5] Virendra C. Patil, Harsha V. Patil , Avinash Patil, Vaibhav Agrawal , Oct-Dec, 2011 "Clinical Profile and outcome of envenomous snake-bite at tertiary care centre in western Maharashtra" , International Journal of Medicine and Public Health, Vol. 1, Issue 4, 28-38

[6] Ruchika Gupta and BVR Reddy, January-June 2011 "GPS and GPRS Based cost effective human tracking system using mobile phones", VIEWPOINT, , volume 2 No.1

[7] Khondker Shajadul Hasan, Mashiur Rahman, 2009,“Cost Effective GPS-GPRS Based Object Tracking System" IMECS, Vol- I,March 18-20,2009, Hong Kong

[8] Yusn,G,Zhang,Z. and Wei Shang Guan, 2006 "Research and Design of GIS in vehicle monitoring system" Proceedings of IEEE 2006

[9] Brahim G, and Luigi L. 2000, “Understanding GPRS : The GSM Packet Radio Service", Computer Networks Journal,34.5, pg.763-779

[10] "GPS Spy Camera-GPS Track” www.gpsspying.com,, Last accessed on $12^{\text {th }}$ Feb 2012

[11] "Solutions on GPS Tracking", www.gpsgagte.com, Last accessed on $10^{\text {th }}$ feb.2012 